\title{
Continuous and noninvasive hemoglobin monitoring reduces red blood cell transfusion during neurosurgery: a prospective cohort study
}

\author{
Wael N. Awada - Maher F. Mohmoued • \\ Tarek M. Radwan - Gomaa Z. Hussien • \\ Hany W. Elkady
}

Received: 11 July 2014 / Accepted: 27 January 2015/Published online: 4 February 2015

(C) The Author(s) 2015. This article is published with open access at Springerlink.com

\begin{abstract}
Continuous, noninvasive hemoglobin ( $\mathrm{SpHb}$ ) monitoring provides clinicians with the trending of changes in hemoglobin, which has the potential to alter red blood cell transfusion decision making. The objective of this study was to evaluate the impact of $\mathrm{SpHb}$ monitoring on blood transfusions in high blood loss surgery. In this prospective cohort study, eligible patients scheduled for neurosurgery were enrolled into either a Control Group or an intervention group (SpHb Group). The Control Group received intraoperative hemoglobin monitoring by intermittent blood sampling when there was an estimated $15 \%$ blood loss. If the laboratory value indicated a hemoglobin level of $\leq 10 \mathrm{~g} / \mathrm{dL}$, a red blood cell transfusion was started and continued until the estimated blood loss was replaced and a laboratory hemoglobin value was $>10 \mathrm{~g} / \mathrm{dL}$. In the $\mathrm{SpHb}$ Group patients were monitored with a Radical-7
\end{abstract}

W. N. Awada $(\varangle) \cdot$ M. F. Mohmoued .

T. M. Radwan - G. Z. Hussien · H. W. Elkady

Department of Anesthesia, ICU and Pain Management, Cairo

University, Manyal, Cairo, Egypt

e-mail: waoool@hotmail.com

M. F. Mohmoued

e-mail: maherfawzym@yahoo.com

T. M. Radwan

e-mail: dtradwan@yahoo.com

G. Z. Hussien

e-mail: neel115@hotmail.com

H. W. Elkady

e-mail: hanimwk@yahoo.com
Pulse CO-Oximeter for continuous noninvasive hemoglobin values. Transfusion was started when the $\mathrm{SpHb}$ value fell to $\leq 10 \mathrm{~g} / \mathrm{dL}$ and was continued until the $\mathrm{SpHb}$ was $\geq 10 \mathrm{~g} / \mathrm{dL}$. Blood samples were taken pre and post transfusion. Percent of patients transfused, average amount of blood transfused in those who received transfusions and the delay time from the hemoglobin reading of $<10 \mathrm{~g} / \mathrm{dL}$ to the start of transfusion (transfusion delay) were compared between groups. The trending ability of $\mathrm{SpHb}$, and the bias and precision of $\mathrm{SpHb}$ compared to the laboratory hemoglobin were calculated. Compared to the Control Group, the SpHb Group had fewer units of blood transfused (1.0 vs 1.9 units for all patients; $p \leq 0.001$, and 2.3 vs 3.9 units in patients receiving transfusions; $p \leq 0.01$ ), fewer patients receiving $>3$ units ( 32 vs $73 \% ; p \leq 0.01$ ) and a shorter time to transfusion after the need was established $(9.2 \pm 1.7$ vs $50.2 \pm 7.9 \mathrm{~min} ; \quad p \leq 0.001)$. The absolute accuracy of $\mathrm{SpHb}$ was $0.0 \pm 0.8 \mathrm{~g} / \mathrm{dL}$ and trend accuracy yielded a coefficient of determination of 0.93. Adding $\mathrm{SpHb}$ monitoring to standard of care blood management resulted in decreased blood utilization in high blood loss neurosurgery, while facilitating earlier transfusions.

Keywords Hemoglobin · Noninvasive monitoring · Transfusion

List of abbreviations

RBC Red blood cell

$\mathrm{Hb} \quad$ Laboratory hemoglobin

$\mathrm{SpHb}$ Continuous and noninvasive hemoglobin monitoring with Pulse CO-Oximetry

ASA American Society of Anesthesiologists

EBL Estimated blood loss

EBV Estimated blood volume 


\section{Introduction}

Red blood cell (RBC) transfusions are initiated to maintain oxygen transport and sustain life but transfusion practices vary widely by hospital, procedure, and physician [1, 2]. Observational studies associate RBC transfusion with risk in the form of postoperative infection [3], impaired pulmonary function [4], and increased length of stay and mortality [5, 6]. Meta-analyses of randomized controlled trials indicate that restrictive transfusion practices are safe and may provide benefit [7]. Additionally, RBC transfusion is costly and a significant contributor to the expense of surgical care [8].

These facts are balanced by the knowledge that anemia, common amongst surgical patients, is also independently associated with adverse outcomes [9]. Therefore, balancing the need for RBC transfusion to mitigate anemia with the risks associated with administration of blood products can be a complicated aspect of care during and after surgery. Laboratory hemoglobin $(\mathrm{Hb})$ values are a primary indicator for the need for blood transfusion [10], but are only available intermittently and results can be delayed in the period between blood draw and laboratory analysis. This means that during surgery, initial and subsequent transfusion decisions are often made without recent $\mathrm{Hb}$ results [1]. In addition to laboratory $\mathrm{Hb}$ values, point-of-care devices such as the HemoCue (HemoCue, Angelhom, Sweden) can be used in the operating room to detect $\mathrm{Hb}$ values; however, this point-of-care device is invasive, and requires intermittent blood sample analysis. The HemoCue also lacks the ability to provide real-time trends, hence limiting its use in guiding blood management decisions [11]. Continuous monitoring of vital signs and estimated blood loss help guide transfusion decisions in the absence of $\mathrm{Hb}$; however, these measures can be inaccurate and misleading [12-14], leading to calls for real-time guidance of blood loss [13].

Continuous and noninvasive hemoglobin $(\mathrm{SpHb})$ monitoring is now possible with Pulse CO-Oximetry technology and multi-wavelength sensors, which also provide traditional pulse oximetry measurements. $\mathrm{SpHb}$ monitoring provides real-time trends in the values of hemoglobin, indicating stable hemoglobin when it may be perceived to be dropping and rising hemoglobin when it may be perceived as not rising fast enough. $\mathrm{SpHb}$ monitoring has been shown to help anesthesiologists reduce RBC transfusion frequency and average units transfused per patient in a randomized controlled trial in moderate to low blood loss orthopedic surgery [15]. The objective of this study was to evaluate $\mathrm{SpHb}$ monitoring impact on RBC transfusions in high blood loss surgery. We hypothesized that the additional information provided by $\mathrm{SpHb}$ monitoring would reduce red blood cell transfusion by preventing over transfusion and decrease the time to start transfusions.

\section{Materials and methods}

\subsection{Eligibility criteria}

The protocol was approved by the Medical Research Ethics Committee of Cairo University Faculty of Medicine. The ethics committee waived the requirement for written informed consent and considered the general surgical informed consent to be sufficient for the study, given Egyptian cultural considerations and the noninvasive nature of monitor and sensors. Patient charts were screened the day prior to scheduled neurosurgery for inclusion and exclusion criteria. A convenience sample of patients who met the criteria was included in a prospective trial conducted between February and August, 2012 in a tertiary care, academic medical center. Adult patients between 15 and 60 years and scheduled to undergo neurosurgical procedure were eligible for the study if they had an American Society of Anesthesiologists (ASA) physical status of I-II. Exclusion criteria included significant liver disease defined as serum alanine aminotransferase and serum aspartate aminotransferase $>2.5$ times normal, significant renal disease defined as serum creatinine $>1.5 \mathrm{mg} /$ $\mathrm{dl}$ or creatinine clearance $<40 \mathrm{ml} / \mathrm{min}$, pregnancy, significant coagulopathy defined as international normalized ratio $>1.5$, use of antiplatelets or anticoagulants, anemic patients with $\mathrm{Hb}$ concentrations less than $10 \mathrm{~g} / \mathrm{dL}$, patients scheduled for procedures with expected low blood loss such as level 1 laminectomy, shunts, nerve decompression, microdiscectomy, etc., and, any patient in whom simultaneous $\mathrm{SpHb}$ and $\mathrm{Hb}$ measurements could not be obtained.

\subsection{Study design}

In this prospective cohort study design, given the limitations on the availability of the device and the number of sensors that were available to use, only one patient scheduled for neurosurgery the next day was randomly selected using the sealed envelope method to be in the $\mathrm{SpHb}$ Group. The remaining patients on that same day were enrolled into a standard care group (Control Group). Envelopes were prepared each day to match the number of enrolled patients. Prior to surgery, patient demographic information (gender, age, estimated weight, ASA status) was recorded. All patients received standard-of-care perioperative monitoring and anesthesia per ASA guidelines by the primary anesthesia care provider. 


\subsection{Study procedures}

Patients in the Control Group received intraoperative $\mathrm{Hb}$ monitoring by intermittent blood sampling analyzed by the central laboratory. An initial blood sample was taken prior to surgery (baseline $\mathrm{Hb}$ ) in all patients. Intra-operatively, blood samples were taken when estimated blood loss (EBL) was $\geq 15 \%$ of total blood volume (Fig. 1). In the $\mathrm{SpHb}$ Group, besides ASA monitoring and laboratory $\mathrm{Hb}$, patients were monitored with a Radical-7 Pulse COOximeter, v7748, connected to a R2-25 adult ReSposable sensor (Revision E, Masimo, Irvine, CA) that displayed continuous $\mathrm{SpHb}$ values. After induction of anesthesia, the $\mathrm{SpHb}$ sensor was placed on the ring finger of the non-

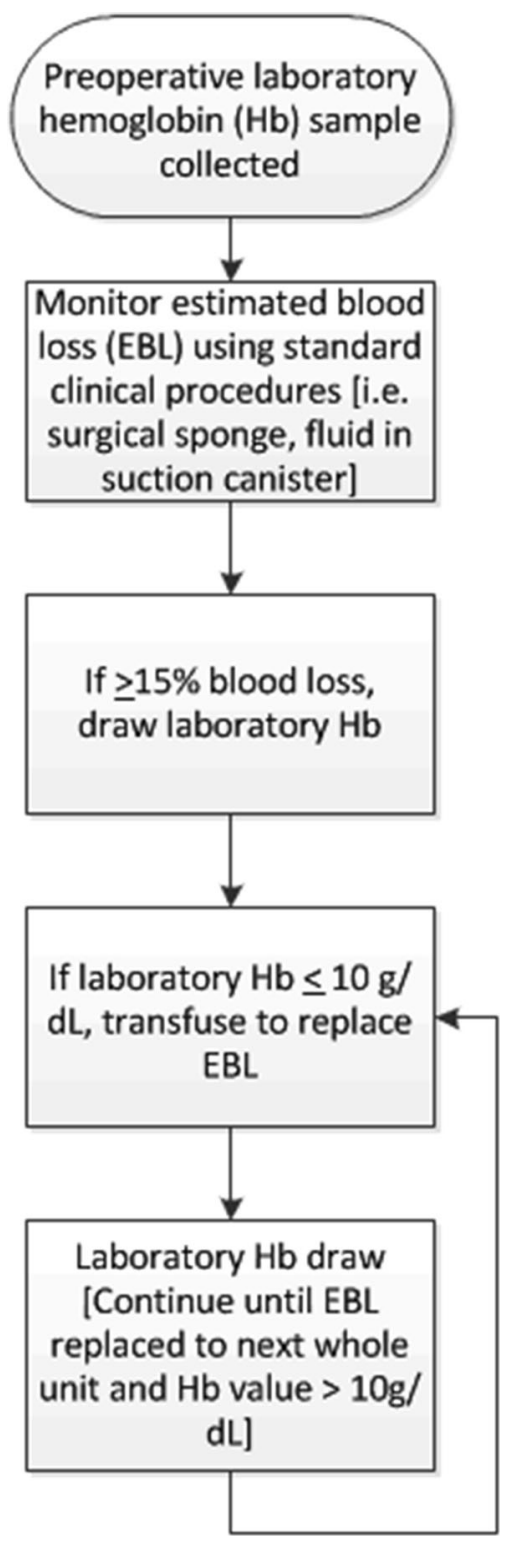

Fig. 1 Flow diagram of $\mathrm{Hb}$ laboratory sample draws dominant hand contralateral to the arterial line with the emitter and detector of the sensor properly aligned per the manufacturer's directions for use. In both groups transfusion was started when $\mathrm{Hb}$ was $\leq 10 \mathrm{~g} / \mathrm{dL}$, was continued until the EBL was replaced to the next whole unit, and an $\mathrm{Hb}$ value was confirmed to be $>10 \mathrm{~g} / \mathrm{dL}$. A blood sample for laboratory analysis was taken prior to surgery (baseline $\mathrm{Hb}$ ), before each transfusion was started, and again when it was discontinued. The $\mathrm{Hb}$ and $\mathrm{SpHb}$ values were recorded on a case report form at baseline and before and after any packed RBC transfusion.

Blood sampling technique was the same for both groups. Arterial blood was drawn from a 20 gauge radial artery cannula into $2 \mathrm{~mL}$ ethylenediaminetetraacetic acid collection tubes, thoroughly mixed then sent immediately to the central lab for analysis by a single hematology analyzer (GEN-S hematology analyzer, Beckman-Coulter Inc., Brea CA). The hematology analyzer was calibrated daily according to the manufactures directions for use and good laboratory practice. All samples were processed and laboratory values returned according to the standard practice of the hospital. The variables recorded for each patient included the time of each blood draw, the start time of each transfusion, and the number of units of blood transfused during the intraoperative period.

All anesthesiologists who participated in the study treated patients in both groups. Blood loss for each patient was estimated by the number of saturated sponges or surgical gauze, the amount of suctioned blood in the waste canister, and the amount of blood in the surgical field. Total blood volume was estimated by multiplying the patient's weight by $75 \mathrm{~mL} / \mathrm{kg}$.

\subsection{Data analysis}

\subsubsection{Sample size calculation}

Historically, at our institution, it has been observed that patients necessitating a blood transfusion would require an average of 1.8 units of blood. Therefore, in order to detect a $33 \%$ reduction in red blood cell units transfused with the addition of $\mathrm{SpHb}$ monitoring (expected effect size equal to 0.6 units) with a standard deviation of 1.0 unit, and assuming a $\alpha$ risk of 0.05 and a $\beta$ risk of $0.20,45$ subjects would be required for each group for a total of 90 patients. Assuming $10 \%$ of enrolled patients would not complete the study we targeted enrollment of a minimum of 99 patients.

\subsubsection{Effect on transfusion}

The following transfusion variables were calculated and compared between the SpHb Group and Control Group: 
(a) average baseline $\mathrm{Hb}$; (b) percent of patients transfused; (c) average amount of blood transfused; (d) average change in $\mathrm{Hb}$ from pre- to post-transfusion, and average amount over or under hemoglobin target post-transfusion; (e) average amount of blood transfused in those who received transfusions; (f) number of patients that received 3 or more units of RBCs; ( $g$ ) the average time between taking the hemoglobin sample or $\mathrm{SpHb}$ measurement, and the start of transfusion (transfusion delay); and, (h) the average total blood loss.

\subsubsection{SpHb absolute and trend accuracy}

To assess absolute accuracy, or single point comparison, paired $\mathrm{SpHb}$ and $\mathrm{Hb}$ measurements were compared preand post-transfusion and bias and standard deviation were calculated. A repeated measures Bland-Altman graph with limits of agreement $(1.96 \times$ standard deviation, adjusted for the bias) was plotted to show agreement across the range of values. To assess trending accuracy, a regression plot of changes in $\mathrm{Hb}$ and corresponding changes in $\mathrm{SpHb}$ was plotted and a coefficient of determination $\left(\mathrm{R}^{2}\right)$ was calculated.

For evaluation of differences between groups, two proportion Z-tests, two sided t-tests or Mann-Whitney rank sum tests for non-normally distributed data were performed, as appropriate, with a $p$ value of $<0.05$ considered statistically significant.

\section{Results}

\subsection{Demographics}

A total of 111 patients were enrolled with five patients excluded due to protocol deviations: three in the Control Group due to massive blood loss requiring transfusion to start before the laboratory result was returned and two in the $\mathrm{SpHb}$ Group due to the time delay between taking the baseline $\mathrm{Hb}$ and the baseline $\mathrm{SpHb}$.

The 106 patients who completed the study were $53 \%$ female and had an average age of $37.6 \pm 14.1$ (mean \pm SD). A total of 45 patients were included in the $\mathrm{SpHb}$ Group and 61 patients were included in the Control Group. A flow diagram of the patient allocation is shown in Fig. 2. Patients were scheduled for various neurosurgical procedures such as frontal, temporal or occipital glioma excisions, meningioma excisions and frontal, temporal and occipital mass excisions. The proportion of surgery types was similar for both groups. Patient demographics are shown in Table 1 with no significant differences between groups except the $\mathrm{SpHb}$ group was lower in weight.

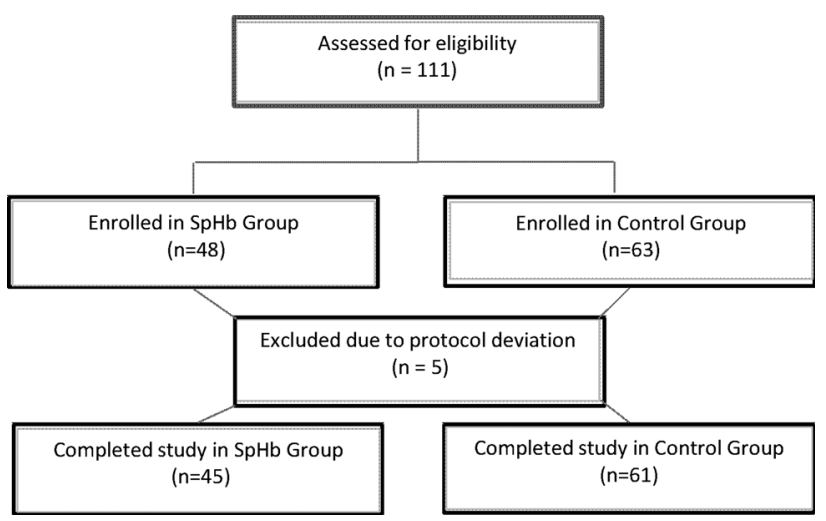

Fig. 2 Flow diagram of screened and included patients

\subsection{Impact on transfusion}

Transfusion variables are shown in Table 2. The SpHb Group had mean baseline hemoglobin of approximately $1 \mathrm{~g} / \mathrm{dL}$ lower than the Control Group. The percentage of patients transfused in each group was not different, but there were fewer RBC units transfused in the $\mathrm{SpHb}$ Group versus the Control Group over all patients (1.0 vs 1.9 units; $p \leq 0.001)$ and in patients receiving transfusions $(2.3 \mathrm{vs}$ 3.9 units; $p \leq 0.0$ 1). The SpHb Group also had a lower percentage of transfused patients receiving $>3 \mathrm{RBC}$ units (32 vs $73 \% ; p \leq 0.01$ ). After RBC transfusion, the $\mathrm{SpHb}$ had a lower $\mathrm{Hb}$ increase after RBC transfusion was initiated $(1.8 \pm 0.9$ vs $2.6 \pm 1.2 \mathrm{~g} / \mathrm{dL} ; p \leq 0.05)$ and shorter time to transfusion after transfusion need was established $(9.2 \pm 1.7$ vs $50.2 \pm 7.9 \mathrm{~min} ; p \leq 0.001)$.

\subsection{Assessment of accuracy}

For assessment of absolute accuracy, $83 \mathrm{SpHb}$ and $\mathrm{Hb}$ comparisons were made (45 baseline, 19 pre-transfusion, and 19 post-transfusion). The bias and standard deviation was $0.0 \pm 0.8 \mathrm{~g} / \mathrm{dL}$ over all comparisons, $0.1 \pm 0.9 \mathrm{~g} / \mathrm{dL}$ for baseline $\mathrm{Hb},-0.1 \pm 0.8 \mathrm{~g} / \mathrm{dL}$ for pre-transfusion $\mathrm{Hb}$ and $-0.1 \pm 0.5 \mathrm{~g} / \mathrm{dL}$ for post-transfusion $\mathrm{Hb}$ values. The Bland-Altman plot for all values showed limits of agreement of -1.6 to $1.5 \mathrm{~g} / \mathrm{dL}$ (Fig. 3).

Trend accuracy analysis (change in consecutive $\mathrm{SpHb}$ values compared to changes in time-matched consecutive $\mathrm{Hb}$ values) showed a coefficient of determination $\left(\mathrm{R}^{2}\right)$ of 0.96 (Fig. 4).

\section{Discussion}

Over 90 million times per year around the world, a physician makes the decision to transfuse blood [16]. Since blood is an organ itself, this "liquid organ transplant" is 
Table 1 Patient characteristics

\begin{tabular}{llll}
\hline & Control group & SpHb group & p value \\
\hline No. of patients & 61 & 45 & - \\
Gender (M/F) (\%) & $49 / 51$ & $44 / 55$ & - \\
Age range (y) & $13-60$ & $12-60$ & 0.66 \\
Weight, range (kg) & $44-76$ & $42-74$ & 0.03 \\
ASA Status I/II (\%) & $78 / 21$ & $64 / 35$ & 0.11 \\
Procedures n (\%) & 61 & 45 & \\
Glioma excision & $12(20)$ & $11(24)$ & \\
Meningioma excision & $11(18)$ & $10(22)$ & \\
Frontal/temporal/occipital mass excision & $4(7)$ & $4(9)$ & \\
Other (e.g. frontal lobectomy, depressed compound skull fracture, & $34(56)$ & $20(44)$ & \\
cerebral vascular anastomosis, pituitary adenoma) & & & \\
\hline
\end{tabular}

Table 2 Transfusion variables

\begin{tabular}{|c|c|c|c|}
\hline & Control group $(\mathrm{n}=61)$ & SpHb group $(n=45)$ & $\mathrm{p}$ value \\
\hline Baseline $\mathrm{Hb}($ mean $\pm \mathrm{SD}, \mathrm{g} / \mathrm{dL})$ & $12.4 \pm 1.6$ & $11.5 \pm 1.0$ & 0.02 \\
\hline Total blood loss $($ mean $\pm \mathrm{SD}, \mathrm{mL})$ & $1,807 \pm 794$ & $1,732 \pm 804$ & 0.30 \\
\hline Percent blood loss (total blood loss/estimated total blood volume) (\%) & $21.7 \pm 16.4$ & $27.7 \pm 25.8$ & 0.18 \\
\hline Pre-transfusion $\mathrm{Hb}($ mean $\pm \mathrm{SD}, \mathrm{g} / \mathrm{dL})$ & $8.3 \pm 1.2$ & $8.6 \pm 1.3$ & 0.23 \\
\hline Post-transfusion $\mathrm{Hb}($ mean $\pm \mathrm{SD}, \mathrm{g} / \mathrm{dL})$ & $10.8 \pm 0.5$ & $10.3 \pm 0.5$ & $<0.01$ \\
\hline Change in $\mathrm{Hb}$, pre-transfusion to post-transfusion (mean $\pm \mathrm{SD}, \mathrm{mL}$ ) & $2.6 \pm 1.2$ & $1.8 \pm 0.9$ & $<0.05$ \\
\hline Patients transfused, n (\%) & $30(49)$ & $19(42)$ & 0.61 \\
\hline $\mathrm{RBC}$ units transfused per patient over all patients (mean $\pm \mathrm{SD}$ ) & $1.9 \pm 2.3$ & $1.0 \pm 1.5$ & 0.01 \\
\hline $\mathrm{RBC}$ units transfused per transfused patient (mean $\pm \mathrm{SD}$, units) & $3.9 \pm 1.7$ & $2.3 \pm 1.5$ & $<0.01$ \\
\hline Transfused patients receiving $>3 \mathrm{RBC}$ units $(\%)$ & 73 & 32 & $<0.01$ \\
\hline Transfusion delay from determination of need (min) & $50.2 \pm 7.9$ & $9.2 \pm 1.7$ & $<0.001$ \\
\hline
\end{tabular}

Transfusion variables for neurosurgery patients in Control Group (standard care hemoglobin monitoring and SpHb Group (SpHb monitoring) for blood management

$S D$ standard deviation

provided with good intentions and is billed as the "gift of life". However, growing data indicate that blood may not always be helpful to the patient and in fact, may expose the patient to unwarranted risks, and hospitals and/or health care systems to unnecessary costs.

Post-operatively, continuous hemoglobin trending could provide added benefit by indicating hemorrhage that is otherwise not apparent. This trending approach aligns well with The Joint Commission's call on hospitals to track appropriateness of transfusions as a quality indicator [17]. Further, the American Medical Association and The Joint Commission have targeted RBC transfusions as one of the top five procedures in medicine for "overuse", defined as using a treatment where the likelihood of benefit is negligible and the patient is exposed to risk of harm [18].

In this study, our primary aim was to determine how a new tool, SpHb monitoring, may impact transfusion decision making in high blood loss surgery when added to standard practice. Our study showed that patients at risk for high blood loss who received $\mathrm{SpHb}$ monitoring received fewer RBC transfusions, on average. In this study, there were no differences in percentage of patients transfused or mean blood loss between the Control and SpHb Groups, indicating that patients and procedures in both groups were similar.

The baseline hemoglobin of the $\mathrm{SpHb}$ Group was approximately $1 \mathrm{~g} / \mathrm{dL}$ lower than the Control Group. Multiple studies have shown that a lower baseline hemoglobin significantly increases the likelihood of receiving a $\mathrm{RBC}$ transfusion [19]. Therefore, the $\mathrm{SpHb}$ group should have been more likely to receive a RBC transfusion in the study. In our study, we observed no difference in the overall transfusion rate (49\% in the Control Group, $42 \%$ in the $\mathrm{SpHb}$ Group) but we did observe a large difference in the number of multi-unit transfusions, leading to a significantly lower average units transfused in the $\mathrm{SpHb}$ group. If both groups in our study had the same baseline hemoglobin, it is possible that we might have also observed 
Fig. 3 Bland and Altman plot of $83 \mathrm{SpHb}$ and $\mathrm{Hb}$ data pairs collected from 45 neurosurgery patients, showing bias (solid line) and limits of agreement (dashed line)

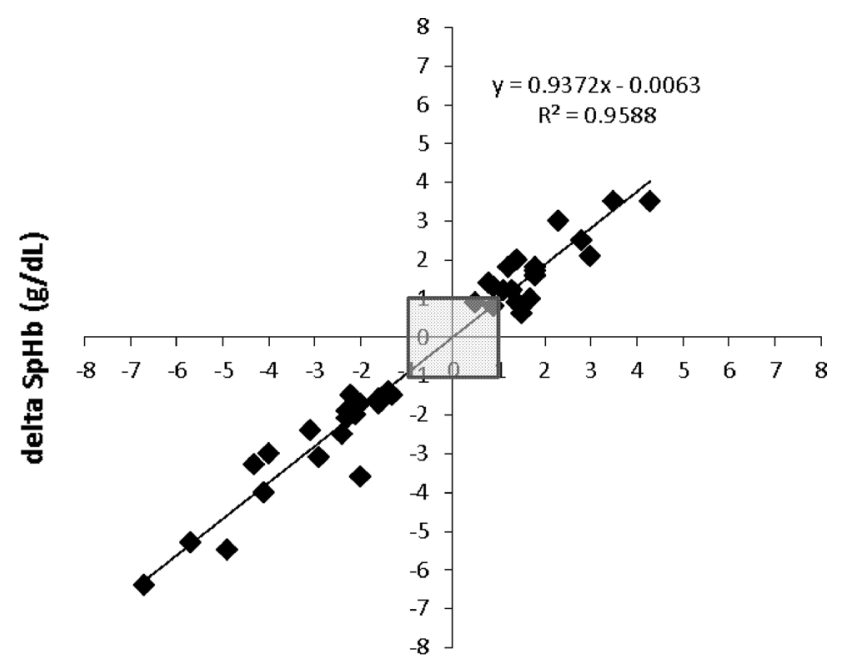

delta $\mathrm{Hb}(\mathrm{g} / \mathrm{dL})$

Fig. 4 Regression plot of directional changes in consecutive $\mathrm{SpHb}$ values (delta $\mathrm{SpHb}, \mathrm{Y}$ axis) compared to consecutive changes in $\mathrm{Hb}$ values (delta $\mathrm{Hb}, \mathrm{X}$ axis), collected from 45 neurosurgery patients. Data points within the shaded area are below the clinically relevant threshold of changes of $\leq 1 \mathrm{~g} / \mathrm{dL}$

a difference in the overall transfusion rate, as was previously shown in a randomized trial of $\mathrm{SpHb}$ monitoring in lower blood loss orthopedic surgery, in which the RBC transfusion rate was $4.5 \%$ in the Control Group and $0.6 \%$ in the SpHb Group [15].

In contrast, the lower average RBC units transfused in our study were primarily due to the differences in multiunit transfusions, as $32 \%$ of the patients in the $\mathrm{SpHb}$ Group received three or more RBC units versus $73 \%$ in the Control Group. This may have occurred due to the ability of the anesthesiologist to gauge in real-time that the transfusion had achieved the desired, increased effect on hemoglobin levels, therefore preventing the decision to have additional RBC units transfused. Further, the real time assessment also affected the initial decision to transfuse, resulting in a quicker decision to initiate a transfusion when needed due to a lack of delay in laboratory Hb values. It is unlikely that the full benefit of continuous monitoring could be achieved by a more diligent assessment of $\mathrm{Hb}$ levels using standard procedures. When using laboratory values, the inherent lag time from the request of a test to obtaining the result would be too great, and using an invasive point-of-care device would still require clinician initiative to request a test, therefore, unexpected changes, or unexpected stabilization of hemoglobin, would not be detected.

It is important to note that although the post-transfusion $\mathrm{Hb}$ was different between groups with the Control Group being higher, the mean post-transfusion hemoglobin of the $\mathrm{SpHb}$ Group was not in the anemic range of $<10 \mathrm{~g} / \mathrm{dL}$. Anemia is a risk factor for surgical patients, but may be of a special concern to neurosurgical patients. Subarachnoid Haemorrhage [20], traumatic brain injury [21], and other neurosurgical patients [22] have worse outcomes if they are anemic.

As a secondary aim, we studied the absolute accuracy and trend accuracy of $\mathrm{SpHb}$. The accuracy of $\mathrm{SpHb}$ has been evaluated in hemodilution [23], surgery [24-29], and intensive care $[11,30]$. Most studies have evaluated absolute accuracy while only a few studies have systematically evaluated trend accuracy, which appears to be more relevant in blood loss assessment. In our study, we verified that 
revision $\mathrm{E}$ sensors for $\mathrm{SpHb}$ monitoring had clinically acceptable absolute accuracy. Laboratory hemoglobin values vary depending on a variety of factors including sampling site. Typically laboratory hemoglobin is measured at the peripheral vein (macrocirculation) reflecting hemoglobin, while $\mathrm{SpHb}$ measures capillary (microcirculation) hemoglobin. Macrocirculation and microcirculation have different physiological responses to acute events, such as blood loss, which must be taken into consideration when making comparison to laboratory values [31, 32].

When $\mathrm{SpHb}$ values were compared to a reference laboratory device in our study, we found a higher standard deviation than what has been reported for $\mathrm{Hb}$ measurements from consecutive blood samples run on the same model lab device [33]. However, the standard deviation of $\mathrm{SpHb}$ to $\mathrm{Hb}$ in our study was similar to that found for $\mathrm{Hb}$ measurements from consecutive blood samples analyzed on two separate laboratory devices [34]. Regarding trend accuracy, the high correlation we observed indicates that increases and decreases in laboratory $\mathrm{Hb}$ were captured with the changes in $\mathrm{SpHb}$. SpHb has the added benefit of not just calculating the differences or lack of differences between intermittent measurements, but also providing data continuously.

In addition to the primary and secondary aims of this study, our results demonstrate that the implementation of $\mathrm{SpHb}$ monitoring could also provide significant cost savings. A 2007 study from Shander et a1. [8] showed annual expenditures on blood and transfusion-related activities, for surgical patients only, ranged from 1.6 to 6 million dollars, or $\$ 522$ to $\$ 1,183$ per $\mathrm{RBC}$ unit. These estimates use activity based costs, which are the true cost of giving blood because they include not just the material cost of blood but also the direct costs to administer blood throughout the multistep procedure. Our results indicate a reduction of 0.9 units of blood per surgery or between $\$ 470$ to $\$ 1,065$ per patient monitored and $\$ 470,000$ to $\$ 1,065,000$ per 1,000 surgeries of the same type (Table 2). Note that this does not include the intra-hospital or even intra-country variability in cost of transfusion, nor the cost of devices and sensors.

Our study has some limitations worth noting. We used a convenience sample and did not randomize all patients after enrollment due to logistics of assigning them to the operating room with a sole $\mathrm{SpHb}$ monitor, but instead randomized which patient would be enrolled in the $\mathrm{SpHb}$ Group. This also led to an expected but unbalanced number of patients in both groups, as we were able to enroll multiple patients on the same day in the Control Group. Nonetheless, there was no bias in $\mathrm{SpHb}$ patient selection and there was no difference in baseline characteristics between groups. Therefore the differences in the $\mathrm{SpHb}$
Group can be attributed to the availability and use of $\mathrm{SpHb}$ monitoring. Furthermore, we were not able to blind the study given that clinicians had to make decisions in realtime data; this decreased the overhead delay in assessing hemoglobin concentrations, and consequently clinicians were able to start and stop transfusions in a timelier manner. While this may be viewed as a study bias, we view the difference of having a continuous data stream as the benefit of $\mathrm{SpHb}$ monitoring rather than a limitation of the study.

Finally, we were not able to collect post-surgery transfusion data or post-discharge information, which would facilitate longer-term assessment of our investigation. Also, our hospital's blood transfusion practice may be different from other hospitals and that may limit transferability of our findings to other institutions. Unless clinical signs dictate otherwise, such as a massive bleeding event during surgery, it is standard practice in our hospital to initiate a hemoglobin measurement when EBL reaches approximately $15 \%$ of estimated blood volume (EBV) and to initiate blood transfusion when the hemoglobin value is confirmed to be $\leq 10 \mathrm{~g} / \mathrm{dL}$.

\section{Conclusion}

Measurement of $\mathrm{Hb}$ is one of the most frequent and important assessments in patients undergoing major surgery and in patients admitted to the critical care unit. Unfortunately, invasive blood sampling and laboratory analysis only offer the perspective of a single point in time, while hemoglobin is in fact dynamic. This means that when the results of the "still picture" taken 5-50 min earlier become available, the "picture" may have changed. Our belief is that the real-time ability of $\mathrm{SpHb}$ [35] offers a "motion picture" that does not replace the metaphorical still picture, but supplements its inherently intermittent and delayed results. As shown in our study, the ability to observe the continuous trend in hemoglobin affects transfusion behavior, allowing earlier cessation of RBC transfusion as well as earlier consideration of initiation of RBC transfusion.

Acknowledgments The authors acknowledge Masimo Corp. for technical review of the manuscript.

Conflict of interest WNA has received travel funds from Masimo Corp. The other authors declare no conflict of interest.

Ethical standards The human subject research, described in this manuscript, complied with Egyptian law at the time of the study.

Open Access This article is distributed under the terms of the Creative Commons Attribution License which permits any use, distribution, and reproduction in any medium, provided the original author(s) and the source are credited. 


\section{References}

1. Frank SM, Savage WJ, Rothschild JA, Rivers RJ, Ness PM, Paul SL, Ulatowski JA. Variability in blood and blood component utilization as assessed by an anesthesia information management system. Anesthesiology. 2012;117(1):99-106.

2. Stover EP, Siegel LC, Parks R, Levin J, Body SC, Maddi R, D'Ambra MN, Mangano DT, Spiess SD. Variability in transfusion practice for coronary artery bypass surgery persists despite national consensus guidelines; a 24-institution study. Institutions of the Multicenter Study of Perioperative Ischemia Research Group. Anesthesiology. 1998;88(2):327-33.

3. Dodd RY. Emerging infections transfusion safety, and epidemiology. N Eng/J Med. 2003;349(13):1205-6.

4. Acheson AG, Brookes MJ, Spahn DR. Effects of allogeneic red blood cell transfusions on clinical outcomes in patients undergoing colorectal cancer surgery; a systematic review and metaanalysis. Ann Surg. 2012;256(2):235-44.

5. Murphy GJ, Reeves BC, Rogers CA, Rizvi SI, Culliford L, Angelini GD. Increased mortality, postoperative morbidity, and cost after red blood cell transfusion in patients having cardiac surgery. Circulation. 2007;116(22):2544-52.

6. Marik PE, Corwin HL. Efficacy of red blood cell transfusion in the critically ill; a systematic review of the literature. Crit Care Med. 2008;36(9):2667-74.

7. Carson JL, Carless PA, Hebert PC. Transfusion thresholds and other strategies for guiding allogeneic red blood cell transfusion. Cochrane Database Syst Rev. 2012;18(4):CD002042.

8. Shander A, Hofmann A, Ozawa S, Theusinger OM, Gombotz H, Spahn DR. Activity-based costs of blood transfusions in surgical patients at four hospitals. Transfusion. 2009;50(4):753-65.

9. Beattie WS, Karkouti K, Wijeysundera DN, Tait G. Risk associated with preoperative anemia in noncardiac surgery: a singlecenter cohort study. Anesthesiology. 2009;110(3):574-81.

10. Carson JL, Grossman BJ, Kleinman S, Tinmouth AT, Marques MR, Fung MK, Holcomb JB, Illoh O, Kaplan LJ, Katz LM, et al. Red blood cell transfusion: a clinical practice guideline from the AABB. Ann Intern Med. 2012;157:49-58.

11. Frasca O, Dahyot-Fizelier C, Catherine K, Levrat Q, Debaene B, Mimoz O. Accuracy of a continuous noninvasive hemoglobin monitor in intensive care unit patients. Crit Care Med. 2011;39(10): 2277-82.

12. Frank M, Schmucker U, Stengel D, Fischer L, Lange J, Grossjohann R, Ekkernkamp A, Matthes G. Proper estimation of blood loss on scene of trauma: tool or tale? J Trauma. 2010;69(5):1191-5.

13. Seruya M, Oh AK, Boyajian MJ, Myseros JS, Yaun AL, Keating RF. Unreliability of intraoperative estimated blood loss in extended sagittal synostectomies. J Neurosurg Pediatr. 2011;8(5): 443-9.

14. Seruya M, Oh AK, Rogers GF, Han KD, Boyajian MI, Myseros JS, Yaun AL, Keating RF. Blood loss estimation during frontoorbital advancement: implications for blood transfusion practice and hospital length of stay. J Craniofac Surg. 23(5):1314-7.

15. Ehrenfeld JM, Henneman J. Impact of continuous and noninvasive hemoglobin monitoring on intraoperative blood transfusions. J Blood Disord Transfus. 2014;5:9. 10.4172/2155-9864.1000237.

16. Hillyer CD, Strauss R, Luban NLC (eds). Handbook of pediatric transfusion medicine. San Diego, CA: Elsevier Inc; 2004.

17. Implementation guide for the Joint Commission patient blood management performance measures. In: The joint commission; 2011.

18. Two Leading Health Care Quality Organizations Hold National Summit to Build Consensus Around Ways to Minimize Overuse of Five Treatments [http://www.jointcommission.org/two leading health care quality organizations hold national summit to build consensus around ways to minimize overuse of five treatments/].

19. Barr PJ, Donnelly M, Cardwell C, Alam SS, Morris K, Parker M, Bailie KE. Drivers of transfusion making and quality of the evidence in orthopedic surgery: a systematic review of the literature. Transf Med Rev. 2011;25:4. doi:10.1016/j.tmrv.2011.04. 003.

20. Naidech AM, Jovanovic B, Wartenberg KE, Parra A, Ostapkovich N, Connolly ES, Mayer SA, Commichau C. Higher hemoglobin is associated with improved outcome after subarachnoid hemorrhage. Crit Care Med. 2007;35(10):2383-9.

21. Salim A, Hadjizacharia P, DuBose J, Brown C, Inaba K, Chan L, Margulies DR. Role of anemia in traumatic brain injury. J Am Coll Surg. 2008;207(3):398-406.

22. McEwen J, Huttunen KH. Transfusion practice in neuroanesthesia. Curr Opin Anaesthesiol. 2009;22(5):566-71.

23. Macknet MR, Allard M, Applegate RL, Rook J. The accuracy of noninvasive and continuous total hemoglobin measurement by pulse CO-oximetry in human subjects undergoing hemodilution. Anesth Analg. 2010;111(6):1424-6.

24. Causey MW, Miller S, Foster A, Beekley A, Zenger O, Martin M. Validation of noninvasive hemoglobin measurements using the Masimo Radical-7 SpHb station. Am J Surg 2011;201(5):590-6.

25. Lamhaut L, Apriotesei R, Combes X, Lejay M, Carli P, Vivien B. Comparison of the accuracy of noninvasive hemoglobin monitoring by spectrophotometry $(\mathrm{SpHb})$ and $\mathrm{HemoCue}(\mathrm{R})$ with automated laboratory hemoglobin measurement. Anesthesiology. 2011;115(3):548-54.

26. Miller RD, Ward TA, Shiboski SC, Cohen NH. A comparison of three methods of hemoglobin monitoring in patients undergoing spine surgery. Anesth Analg. 2011;112(4):858-63.

27. Berkow L, Rotolo S. Mirski E; Continuous noninvasive hemoglobin monitoring during complex spine surgery. Anesth Analg. 2011;113(6):1396-402.

28. Butwick A, Hilton G, Carvalho B. Non-invasive haemoglobin measurement in patients undergoing elective Caesarean section. Br J Anaesth. 2012;108(2):271-7.

29. Applegate RL, II, Barr Sf, Collier CE, Rook JL, Mangus DB, Allard MW. Evaluation of pulse cooximetry in patients undergoing abdominal or pelvic surgery. Anesthesiology. 2011;116(1): $65-72$.

30. Coquin J, Dewitte A, Le Manach V, Caujolle M, Joannes-Boyau O, Fleureau C, Janvier G, Ouattara A. Precision of noninvasive hemoglobin-level measurement by pulse co-oximetry in patients admitted to intensive care units for severe gastrointestinal bleeds. Crit Care Med. 2012;40(9):2576-82.

31. Daae LN, Halvorsen S, Mathisen PM, Mironska K. A comparison between haematological parameters in 'capillary' and venous blood from healthy adults. Scand J Clin Lab Invest. 1988;48: 723-6.

32. Neufeld L, Garcia-Guerra A, Sanchez-Francia D, Newton-Sanchez O, Ramirez-Villalobos MD, Rivera-Dommarco J. Hemoglobin measured by Hemocue and a reference method in venous and capillary blood: a validation study. Salud Publica Mex. 2002;44:219-27.

33. Gehring H, Duembgen L, Peterlein M, Hagelberg S, Dibbelt L. Hemoximetry as the "gold standard"? Error assessment based on differences among identical blood gas analyzer devices of five manufacturers. Anesth Analg. 2007;105(6 Suppl):S24-30.

34. Rippmann CE, Nett PC, Popovic D, Seifert B, Pasch T, Spahn DR. Hemocue, an accurate bedside method of hemoglobin measurement? J Clin Monit. 1997;13(6):373-7.

35. Lacroix J, Tucci M. Noninvasive or invasive hemoglobin measurement? Crit Care Med. 40(9):2715-6. 